agreement with the principles of the new European Union Standards for Tuberculosis Care [5].

Ana Antunes*, Joana Gomes*, Inês Belchior ${ }^{\#}$, Ana Isabel Loureiro", Aurora Carvalho ${ }^{*,+}$, Anabela Madeira ${ }^{\S}$ and Raquel Duarte $^{*,+, f, * *}$

${ }^{*}$ Centro Hospitalar Vila Nova de Gaia/Espinho, EPE, ${ }^{+} \mathrm{CDP}$ de Vila Nova de Gaia, Vila Nova de Gaia, "Hospital Sao Joao, EPE, ${ }^{f}$ Centro de Referência Regional do Norte de Tuberculose Multirresistente, ${ }^{* *}$ Faculdade de Medicina da Universidade do Porto, Porto, "Centro Hospitalar Trás-os-Montes e Alto Douro, Vila Real, and ${ }^{\S}$ Associação Nacional de Farmácias, Lisbon, Portugal.

Correspondence: A. Antunes, Centro Hospitalar Vila Nova de Gaia/Espinho, EPE, R Conceiçao Fernandes, Vila Nova de Gaia, Portugal. E-mail: ana.oliveirinha2@gmail.com
Statement of Interest: None declared.

\section{REFERENCES}

1 Yew WW, Lange C, Leung CC. Treatment of tuberculosis: update 2010. Eur Respir J 2011; 37: 441-462.

2 World Health Organization. Treatment of tuberculosis - guidelines for national programmes, 4th Edn. Geneva, World Health Organization, 2009.

3 ARS Norte. Congresso Internacional de Cuidados Paliativos. [International Congress on Palliative Care.] www.arsnorte.min-saude. pt/portal/page/portal/ARSNorte Date last accessed: April 30, 2011.

4 Juan $G$, Lloret $T$, Perez $C$, et al. Directly observed treatment for tuberculosis in pharmacies compared with self-administered therapy in Spain. Int J Tuberc Lung Dis 2006; 10: 215-221.

5 Migliori GB, Zellweger JP, Abubakar I, et al. European Union Standards for Tuberculosis Care. Eur Respir J 2012; 39: 807-819.

DOI: $10.1183 / 09031936.00005012$

\title{
Predicting survival in mesothelioma
}

\section{From the author:}

Thank you for the opportunity to respond to the thoughtful letter from J.G. Smith [1].

The main issues she raises stem from the original paper having aims other than use for prediction in current individual or legal cases. Our main aim was to describe the epidemiology of malignant mesothelioma in Western Australia and to demonstrate how little improvement there has been in survival over the last $30 \mathrm{yrs}$, despite large changes in treatment [2]. Thus, we fitted survival models to all available data. The complicated age terms were just the best-fitting fractional polynomial fit to these data. Further analyses revealed that the $\mathrm{u}$-shaped survival with age was caused by the comparatively poor survival in patients diagnosed under the age of $40 \mathrm{yrs}$, such that when these were excluded from analysis, a linear decline in age was the best fit. We also included all patients with an unknown site of mesothelioma, leading to the apparently anomalous better survival in this group.

We suggest that if a survival model is to be developed and used for individual prediction (possibly in legal cases), we would need to exclude: patients who were diagnosed at death; possibly all those with unrecorded histology; all those with unspecified site of disease; and possibly all those diagnosed before 1980 (or maybe 1990 or later).
To that end, we have spoken with J.G. Smith and suggested that we work together with the necessary subset of the data (which may soon include an additional year of accrued cases) in order to produce a revised publishable model that would have much greater utility in the context for which she wishes to use it.

\section{Arthur William Musk*,\#}

*Dept of Respiratory Medicine, Sir Charles Gairdner Hospital, Nedlands, and "Medicine and Population Health, University of Western Australia, Crawley, Australia.

Correspondence: A.W. Musk, Department of Respiratory Medicine, Sir Charles Gairdner Hospital, Nedlands WA 6009, Australia. E-mail: Bill.Musk@health.wa.gov.au

Statement of Interest: None declared.

\section{REFERENCES}

1 Smith JG. Predicting survival in malignant mesothelioma. Eur Respir J 2012; 40: 799.

2 Musk AW, Olsen N, Alfonso $\mathrm{H}$, et al. Predicting survival in malignant mesothelioma. Eur Respir J 2011; 38: 1420-1424.

DOI: $10.1183 / 09031936.00102612$ 